\title{
Antibiotic Susceptibility Pattern of Nalidixic Acid Resistant Salmonella Isolates in Shree Birendra Hospital Chhauni
}

\author{
Dhirendra Kunwar', Sabita Bhatta ${ }^{2}$, Raina Chaudhary², Komal Raj Rijal ${ }^{1 *}$ \\ ${ }^{1}$ Central Department of Microbiology, Tribhuvan University, Kirtipur, Nepal. \\ ${ }^{2}$ Nepal Army Institute of Health Science, Shree Birendra Hospital, Chhauni, Kathamandu.
}

*Corresponding author: Komal Raj Rijal, Central Department of Microbiology, Tribhuvan University, Kirtipur, Kathmandu; Email: rijalkomal@yahoo.com

\begin{abstract}
Objectives: This study was aimed to know the prevalence of Nalidixic acid resistant Salmonella isolates and their antibiotic susceptibility pattern.

Methods: A total of 4619 febrile patients suspecting the cases of typhoid fever by clinician, attending at Shree Birendra hospital during May- November 2013 were subjected to culture. Blood sample $(5 \mathrm{ml})$ was collected from the suspected cases and inoculated immediately into $45 \mathrm{ml}$ of Brain heart infusion broth (BHI) and further processed for the identification of Salmonella Typhi and S. Paratyphi. Antimicrobial susceptibility pattern of $S$. Typhi and $S$. Paratyphi isolates were determined by the modified Kirby-Bauer disc diffusion method.
\end{abstract}

Results: Out of 4619 blood sample, $8.7 \%(n=403)$ sample were culture positive. Among culture positive, $66.3 \%(n=267)$ cases were $S$. Typhi, $26.1 \%(n=105)$ cases were $S$. Paratyphi and $7.7 \%(n=31)$ were other than Salmonella isolates respectively. Out of 372 Salmonella isolates, most of the S. Typhi isolates i.e. $95.51 \%(n=255)$ and S. Paratyphi isolates i.e. $97.14 \%(n=102)$ are highly resistant to nalidixic acid. Most of these isolates were also found resistant to ciprofloxacin and ofloxacin.

Conclusion: Therefore, screening of nalidixic acid susceptibility might be done prior to prescribe the drug for the treatment of enteric fever.

Key words: Blood culture, Nalixidic acid, Salmonella, enteric fever

\section{INTRODUCTION}

The term enteric fever consists of both typhoid and paratyphoid fevers (Lesser and Miller 2003). Typhoid and paratyphoid fever remain important public health problems globally and major causes of morbidity in the developing world including Nepal (Bukle et al. 2010; Acharya et al. 2012). Enteric fever caused by $S$. Typhi and $S$. Paratyphi A is the most common clinical diagnosis among febrile patients presenting to hospital in Nepal (Acharya et al. 2012). Although a wide range of Salmonella serotypes may cause human disease, broadly grouped into several typhoidal species that are specific human pathogens and includes serotypes S. Typhi and S. Paratyphi, and other serotypes that are primarily spread to humans from animal sources are non-typhoidal (Laupland et al. 2010). However, non-typhoidal Salmonella can also cause a variety of life-threatening extra-intestinal infections. Typhoid is unique to human, characterized by malaise, fever, abdominal discomfort, transient rash, splenomegaly, hepatomegaly, bradycardia, and leucopenia, the most prominent major complications are intestinal hemorrhage, and perforation. The real impact of typhoid fever is difficult to estimate because the clinical picture is confused with other febrile infections (Saleh 2013). Therefore, this study was aimed to know the prevalence of Nalidixic acid resistant Salmonella isolates and their antibiotic susceptibility pattern.

\section{MATERIALS AND METHODS}

This study was conducted at Shree Birendra Hospital, Chauni, Kathmandu during May to November, 2013. A total of 4619 blood samples were collected from the patients suspected of enteric fever. The blood samples were collected by veni-puncture under aseptic condition and then collected sample was transferred in BHI broth (3ml or $5 \mathrm{ml}$ blood in $45 \mathrm{ml}$ of brain heart infusion broth). It was then subjected to culture for Salmonella at $37^{\circ} \mathrm{C}$ and sub-cultured on MacConkey agar (MA) after every 24 hours of incubation. On the next day, tiny nonlactose fermenting colonies on MA was then processed for identification according to standard microbiological methods (microscopic examination, biochemical tests) (Cheesbrough, 2000). The isolates were then subjected to 
antimicrobial susceptibility testing by modified KirbyBauer disk diffusion method following clinical and laboratory standard institute (CLSI) guideline on MullerHinton agar plates (Cheesbrough, 2000; CLSI 2011). The antibiotics used were: nalidixic acid, amoxycilin (10 $\mu \mathrm{g})$, ceftriaxone $(30 \mu \mathrm{g})$, cephotaxime $(30 \mu \mathrm{g})$, chloramphenicol $(30 \mu \mathrm{g})$, ciprofloxacin $(5 \mu \mathrm{g})$, co-trimoxazole $(25 \mu \mathrm{g})$, and ofloxacin (5 $\mu g$ ) (Hi Media., Mumbai, India) (CLSI 2011).

\section{RESULTS}

Out of 4619 blood specimens cultured, only 403 (8.7\%) samples had shown bacterial growth. Out of 403, 372 $(92.31 \%)$ were identified as Salmonella isolates. Among the Salmonella isolates, 267(66.2\%) were Salmonella Typhi and $105(26.1 \%)$ were Salmonella Paratyphi A (Table 1).

Table 1: Month wise distribution of Salmonella isolates

\begin{tabular}{lcccccc}
\hline \multirow{2}{*}{ Month } & \multicolumn{2}{c}{ S.Typhi } & \multicolumn{2}{c}{ S. ParatyphiA } & \multicolumn{2}{c}{ Total Salmonella isolates } \\
\cline { 2 - 7 } & Number & $\%$ & Number & $\%$ & Number & $\%$ \\
\hline May & 22 & 8.2 & 13 & 12.4 & 35 & 9.4 \\
June & 98 & 36.7 & 23 & 21.9 & 121 & 32.5 \\
July & 52 & 19.5 & 22 & 21.0 & 74 & 19.9 \\
August & 54 & 20.2 & 12 & 11.4 & 66 & 17.7 \\
September & 20 & 7.5 & 22 & 21.0 & 42 & 11.3 \\
November & 21 & 7.9 & 13 & 12.3 & 34 & 9.2 \\
\hline Total & 267 & 100 & 105 & 100 & 372 & 100 \\
\hline
\end{tabular}

Out of total Salmonella Typhi isolated, nalidixic acid 255 (95.5\%), ciprofloxacin 257 (96.3\%), and ofloxacin 257 $(96.3 \%)$ were found to be resistant to respective drugs whereas commonly used drug chloramphenicol 265 $(99.3 \%)$ still found to be effective (Table 2 ).

Table 2: Antibiotic susceptibility pattern of $S$. Typhi

\begin{tabular}{lccccc}
\hline \multirow{2}{*}{ Antibiotics } & \multicolumn{2}{c}{ Sensitive } & \multicolumn{2}{c}{ Resistance } & \multirow{2}{*}{ Total } \\
\cline { 2 - 5 } & Number & $\%$ & Number & $\%$ & \\
\hline Nalidixic Acid & 12 & 4.5 & 255 & 95.5 & \\
Amoxycilin & 261 & 97.8 & 6 & 2.2 & \\
Cotrimoxazole & 264 & 98.9 & 3 & 1.1 & \\
Ceftriaxone & 261 & 97.8 & 6 & 2.2 & \\
Cephotaxime & 263 & 98.5 & 4 & 1.5 & \\
Chloramphenicol & 265 & 99.3 & 2 & 0.7 & \\
Azithromycin & 263 & 98.5 & 4 & 1.5 & \multirow{2}{*}{267} \\
Ciprofloxacin & 10 & 3.7 & 257 & 96.3 & \\
Ofloxacin & 10 & 3.7 & 257 & 96.3 & \\
\hline
\end{tabular}

Out of 105 Salmonella Paratyphi A isolates, cotrimoxazole 104 (99\%), ceftriaxone 104 (99\%), and chloramphenicol 104 (99\%) were found to be sensitive whereas nalidixic acid 102(97.1), ciprofloxacin 102 (97.1\%) and ofloxacin102 (97.1\%) were found to be highly resistant (Table 3).

Table 3: Antibiotic susceptibility pattern of $S$. ParatyphiA

\begin{tabular}{lllllll}
\hline \multirow{2}{*}{ Antibiotics } & \multicolumn{2}{c}{ Sensitive } & \multicolumn{2}{c}{ Resistance } & \multirow{2}{*}{ Total } \\
\cline { 2 - 5 } & \multicolumn{1}{c}{ Number } & \multicolumn{2}{c}{$\%$} & Number & $\%$ & \\
\hline Nalidixic Acid & 3 & 2.9 & 102 & 97.1 & \\
Amoxycilin & 97 & 92.4 & 8 & 7.6 & \\
Cotrimoxazole & 104 & 99 & 1 & 1 & \\
Ceftriaxone & 104 & 99 & 1 & 1 & \\
Cephotaxime & 102 & 97.1 & 3 & 2.9 & \\
Chloramphenicol & 104 & 99 & 1 & 1 & \\
Azithromycin & 97 & 92.4 & 8 & 7.6 & \\
Ciprofloxacin & 3 & 2.9 & 102 & 97.1 & \\
Ofloxacin & 3 & 2.9 & 102 & 97.1 & \\
\hline
\end{tabular}


Out of the total Salmonella isolates, 357(95.97 \%) were NARS isolates which included both S. Typhi 255 isolates and S. Paratyphi A 102 isolates respectively.
Out of total S. Typhi isolates $95.51 \%$ and S. Paratyphi A, $97.14 \%$ were NARS. (Table 4 )

Table 4: Nalidixic acid susceptibility pattern Salmonella isolates

\begin{tabular}{|c|c|c|c|c|c|c|c|}
\hline \multirow{3}{*}{$\begin{array}{l}\text { Bacterial } \\
\text { isolates }\end{array}$} & \multicolumn{6}{|c|}{ Antibiotic susceptibility pattern of Nalidixic acid } & \multirow{3}{*}{ Total } \\
\hline & \multicolumn{3}{|c|}{ Resistance } & \multicolumn{3}{|c|}{ Sensitive } & \\
\hline & Male & Female & Total & Male & Female & Total & \\
\hline S. Typhi & 191 & 64 & $255(95.51 \%)$ & 8 & 4 & $12(4.49 \%)$ & 267 \\
\hline S. Paratyphi & 78 & 24 & $102(97.14 \%)$ & 3 & 0 & $3(2.86 \%)$ & 105 \\
\hline Total & 269 & 88 & $\begin{array}{c}357 \\
(95.97 \%)\end{array}$ & 11 & 4 & $\begin{array}{c}15 \\
(4.03 \%)\end{array}$ & 372 \\
\hline
\end{tabular}

\section{DISCUSSION}

Enteric fever is a disease of concern in developing countries like Nepal and remains endemic in the capital city Kathmandu due to lack of supply of clean drinking water, poor sanitation, and cross-contamination of water supply with sewerage (Pokharel et al. 2009). Various researchers reported wide variation in the sensitivity patterns of various Salmonella strains circulating in different geographic regions of Nepal, so it is essential to assess the sensitivity of Salmonella serotypes to antibiotics before instituting empirical therapy (Arora et al. 2010). We attempted to evaluate antibiotic susceptibility patterns in blood isolates of Salmonella serotypes from Shree Birendra Army hospital in Kathmandu with a view to understanding current trends in antibiotic sensitivity patterns.

In this study, out of 4,619 specimens processed for culture, only $403(8.7 \%)$ isolates had shown growth, i.e. 267(66.2\%) were Salmonella Typhi and 105 (26.1\%) were Salmonella Paratyphi. This is not in similar with the results of other studies in different parts of Nepal, where $S$. Paratyphi A had reported main causative organism for enteric fever. S. Typhi $(8.96 \%)$ and $S$. Paratyphi A (13.17\%) (Pokharel et al. 2006; Shirakawa et al. 2006; Pokharel et al. 2009). In this study, most of the febrile cases and diagnosed enteric fever cases were from month between June-July (121), July-August (74), and August-September (66). Similar results also have shown by Malla et al. (2005) and Acharya et al. (2012) i.e. the peak occurrence of enteric fever in summer and rainy season (Malla et al. 2005; Acharya et al. 2012). The reason behind such result may be at this time; temperature and rainfall are relatively high and higher chance of mixing sewage to water supply pipelines due to unmanaged water supply system in Kathmandu Valley.In this study, most of $S$. Typhi isolates werehighly sensitive with amoxycillin, co-trimoxazole, ceftriaxone, cephotaxime, chloramphenicol and azithromycin but they are highly resistant to nalidixic acid, ciprofloxacin and ofloxacin. Amoxicillin, Chloramphenicol and Cotrimoxazole (ACCo) were found to be effective having efficacy rate of $97.8 \%, 98.9 \%$ and $99.3 \%$ respectively. Similarly, most of Salmonella Paratyphi A isolates were highly sensitive with Amoxycillin, Co-trimoxazole, Ceftriaxone, Cephotaxime, Chloramphenicol and Azithromycin. This study revealed a re-emergence of susceptibility to amoxicillin, chloramphenicol and cotrimoxazole in greater proportion than reported by other similar studies conducted in different parts of Nepal at different times (Sharma et al. 2003; Bhatta et al. 2005; Pokharel et al. 2006). In this study, the nalidixic acid resistance in S. Typhi was found to be $95.5 \%$ and in S. Paratyphi A was found to be $97.1 \%$ which is in agreement with the findings of Prajapati 2009 (Prajapati 2009). Furthermore, isolation of the higher frequency of nalidixic acid-resistant Salmonella isolates found in this study indicates the possibility of fluoroquinolone resistance occurring in near future as a consequence of the haphazard use of fluoroquinolones without antibiotic susceptibility test.

The major limitations of this study were limited sample size and short duration of time. Furthermore, the samples were collected from a tertiary care center, so cases that preferred to seek health care in local settings were missed. The inclusion of patients from different geographic areas would have been helpful for more specific results. Furthermore, minimum inhibitory concentration (MIC) value of the antibiotics was not calculated. Molecular identification and characterization of isolates werenot performed due to the unavailability of equipment and resources in this setting.

\section{CONCLUSION}

The higher sensitivity of third generation cephalosporins (ceftriaxone and cephotaxime) and macrolide (azithromycin) indicates that these drugs along with chloramphenicol and cotrimoxazole may 
still be considered as better options for the treatment of enteric fever. Hence cephalosporins remain the alternative drugs against infections with ciprofloxacin resistant Salmonella isolates. Therefore, the use of cephalosporins in the empirical therapy, misuse and over use should be discouraged. Resistance to nalidixic acid as a screening test for detecting reduced susceptibility to the fluoroquinolones helps in early diagnosis and substitution of appropriate antibiotic therapy which is very important in the management of enteric fever.

\section{ACKNOWLEDGEMENTS}

Authors would like to thank all staffs of Central Department of Microbiology, Tribhuvan University and Medical Superintendents, doctors, nurses, staffs and patients of the Shree Birendra hospital for their kind support during the study.

\section{REFERENCES}

Acharya A, Nepal HP, Gautam R and Shrestha S (2012) Enteric fever pathogens and their antimicrobial susceptibility pattern in Chitwan. Journal of Chitwan Medical College. 1: 26-30.

Arora D, Singh R, Kaur M and Ahi RS (2010) A changing pattern in antimicrobial susceptibility of Salmonella enterica serotype isolated in north India. Afr J Microbiol Res 4: 197-203.

Bhatta CP, Bhuyan KC and Maharjan A (2005) Antibiotic sensitivity pattern of Salmonella species isolated from blood culture. J Nepal Health Res Counc 3: 35-38.

Buckle GC, Walker CLF and Black RE (2010) Typhoid fever and paratyphoid fever: systematic review to estimate global morbidity and mortality for 2010 . Journal of Global Health. 2: 1-9.

Cheesbrough M (2000) District Laboratory practice in tropical countries Part II. Cambridge University Press, Low Price edition, India, 2000; 196-274.

Clinical and Laboratory Standard Institute (CLSI) (2011) Performance standards for antimicrobial susceptibility testing; Twenty First Information Supplement. CLSI approved standard M100-S20. CLSI, Wayne PA.

Laupland KB, Schonheyder HC, Kennedy KJ, Lyytikainen O, Valiquette L, Galbraith J and Collignon P (2010) Salmonella Enterica bacteriamia: A multinational population based cohort study. BMC Infectious Dis 10: 95-101.

Lesser CF and Miller SI (2003) Salmonellosis In : Braunwald E, Fauci AS, Kasper DL, Hauser ST, Lango DL and Jameson JL (eds) Harrison's Principle of Internal Medicine, $15^{\text {th }}$ edn, McGraw Hill, India: 970-974.

Malla S, Kansakar P, Serichantalergs O, Rahman M and Basnet S (2005). Epidemiology of typhoid and paratyphoid fever in Kathmandu: two years study and trends of antimicrobial resistance. $J$. Nepal Med Assoc 44: 18-22.

Pokharel BM, Koirala J, Dahal RK, Mishra SK, Khadga PK and Tuladhar NR (2006) Multidrug-resistant and extended-spectrum beta-lactamase (ESBL)producing Salmonella enterica (serotypes Typhi and Paratyphi A) from blood isolates in Nepal: surveillance of resistance and a search for newer alternatives. Int J Infect Dis 10: 434-438.

Pokharel P, Rai S, Karki G, Katuwal A, Vitrakoti R and Shrestha $S$ (2009) Study of enteric fever and antibiogram of Salmonella isolates at a Teaching Hospital in Kathmandu Valley. Nepal Med Coll J 11: 176-178.

Prajapati KC (2009) Antibiotic susceptibility pattern of Salmonella from blood of suspected enteric fever patients attending Patan Hospital. M.Sc. Dissertation submitted to Central Department of Microbiology, Tribhuvan University pp. 37-42.

Saleh MAD (2013) Comparison of widal agglutination test with ELISA Typhi test for serological diagnosis of Typhoid fever in some Iraqi patients. International Journal of Advanced Research 1(5): 133-142.

Sharma N, Koju R, Karmacharya B, Tamang MD, Makaju R, Nepali N, Shrestha P and Adhikari D (2003) Typhoid fever in Dhulikhel hospital, Nepal. Kathmandu Univ Med J 2: 188-192.

Shirakawa T, Acharya B, Kinoshita S, Kumagai S, Gotoh A and Kawabata M (2006) Decreased susceptibility to fluoroquinolones and gyrA gene mutation in the Salmonella enterica serovar Typhi and Paratyphi A isolated in Katmandu, Nepal, in 2003. Diagn Microbiol Infect Dis 54: 299-303. 